\title{
Une année avec Claude Simon
}

\section{Benoît Peeters}

\section{(2) OpenEdition}

\section{Journals}

Édition électronique

URL : http://journals.openedition.org/ccs/500

DOI : $10.4000 /$ ccs. 500

ISSN : 2558-782X

\section{Éditeur :}

Presses universitaires de Rennes, Association des lecteurs de Claude Simon

\section{Édition imprimée}

Date de publication : 31 décembre 2006

Pagination : 107-108

ISBN : 9782914518895

ISSN : 1774-9425

\section{Référence électronique}

Benoît Peeters, «Une année avec Claude Simon », Cahiers Claude Simon [En ligne], 2 | 2006, mis en ligne le 20 septembre 2017, consulté le 15 septembre 2020. URL : http://journals.openedition.org/ccs/ 500

Cahiers Claude Simon 


\title{
Une année avec Claude Simon
}

\author{
par Benoît PEETERS
}

De juin 1975 à l'été qui a suivi, il me semble avoir vécu dans une constante intimité avec Claude Simon. J'avais entamé l'écriture d'Omnibus, pastiche en même temps que vie rêvée de cet écrivain qui me donnait le sentiment d'avoir accompli à l'avance, et à la perfection, ces livres que je n'avais pas commencé d'écrire.

Une année durant, dans ma petite chambre de la rue de l'Estrapade, j’ai baigné dans la fascination des œuvres de Simon, transporté par les alluvions que charrient leurs phrases enveloppantes. J'accompagnais Simon dans la Débâcle de 40, je combattais en Espagne à ses côtés, je plongeais au cœur de provinces perdues, sur les traces de ses ancêtres. Avidement, je collectais les anecdotes les plus infimes, les textes les plus oubliés, passant et repassant place Monge, devant l'immeuble qu'il habitait. Je fus bouleversé, un jour, de le voir sortir de chez lui pour acheter Le Monde. Il m'arriva même d'envoyer à L'Express une lettre que je signai de son nom, à propos de la prochaine parution de Leçon de choses, lettre qu'il aurait sans doute pu signer mais qu'il lui fallut bizarrement démentir, quelques semaines plus tard (y a-t-il aujourd'hui prescription ?).

Le début du manuscrit, sur lequel j'avais travaillé une bonne partie de l'été, disparut un soir, sur la route de Versailles à Paris, un cahot l'ayant fait tomber du porte-bagages de mon vélomoteur. Désespéré, j'arpentai longuement l'avenue avant de me résoudre à la 
perte de mon trésor. Rentré dans ma chambre, je réécrivis ces pages de mémoire, presque mot pour mot je crois (d'un tel exploit, fautil le dire, je serais incapable aujourd'hui). Tout au long de l'année, sitôt les cours terminés, je continuai le texte dans un curieux mélange d'insouciance et de contraintes, sans savoir ce qui adviendrait cinq mots plus loin, à tel point qu'ayant lu un jour le premier chapitre à une amie, lorsqu' elle me demanda de lui raconter la suite, je dus lui avouer que je l'ignorais à peu près autant qu'elle.

Dans les pages d'Omnibus, irrespectueux autant qu'admiratif, j'enivre Claude Simon et je le fais mourir, je lui attribue le prix Nobel qu'il méritait déjà, mais j'écris à sa place son discours et lui retire la paternité de ses livres. Voulant m'arracher à l'emprise de son œuvre, je tentais une sorte de pastiche intégral, où j'aurais tout repris, tout remixé: ses thèmes et son style, des morceaux de sa vie et les procédés de ses diverses périodes. Omnibus est comme une réécriture follement accélérée du Nouveau Roman, tel que Jean Ricardou l'avait minutieusement décrit, c'est un texte libre et crypté à la fois rempli d'anagrammes et d'acrostiches, d'allusions et de citations cachées. Bien des détails, qui nous semblaient alors évidents (à moi et aux quelques amis qui fréquentaient les colloques de Cerisy), sont devenus des plus opaques. Mais j'espère qu'il reste quelque chose du mélange de ferveur et de jubilation dans lequel ces pages furent écrites.

Ce drôle d'hommage avait tout pour irriter ; et plusieurs pensaient, lorsque j'achevai Omnibus, que cette biographie plus qu'à moitié imaginaire ne pourrait jamais paraître. Je serai donc toujours reconnaissant à Claude Simon de l'accueil qu'il réserva au manuscrit que je lui avais envoyé, en même temps qu’à Jérôme Lindon. L'histoire s'acheva de manière plus heureuse : dix ans après la parution d'Omnibus, l'Académie de Stockholm décernait à Claude Simon le Prix Nobel de littérature. Aucun incident ne vint troubler le discours qu'il prononça ce jour-là. 